tratamento endodôntico. Materiais e métodos: A presente revisão sistemática foi orientada de acordo com as recomendações PRISMA (Preferred Reporting Items for Systematic Reviews and Meta-Analyses). A avaliação do risco de viés foi baseada nos critérios definidos pela Colaboração Cochrane, e adaptados a estudos in-vitro. Realizou-se uma revisão bibliográfica, sem restrições de idioma, com a expressão de pesquisa (endodontic retreatment OR canal retreatment OR retreatment OR root canal retreatment) AND solvent* AND (filling material OR obturation materials), recorrendo às bases de dados PubMed, EBSCOhost (Dentistry, Oral Sciences Source), Cochrane Library, Scopus e Web of Science. Foram incluídos estudos realizados em dentes permanentes humanos que avaliaram, através de micro-CT, a quantidade de material remanescente após utilização de solventes durante o retratamento. Artigos de revisão, casos clínicos e estudos realizados em dentes de bovino ou em dentes artificiais foram excluídos. Resultados: A pesquisa resultou em 580 artigos, dos quais 353 foram selecionados após análise de títulos e resumos. 7 artigos preencheram os critérios de elegibilidade e foram selecionados. O risco global de viés foi considerado alto. Devido a variações metodológicas entre os artigos incluídos não se prosseguiu para a meta-análise. Foram utilizados diferentes solventes (óleo de laranja, xileno, clorofórmio, eucaliptol e EndoSolv R) com diferentes protocolos, impedindo uma comparação direta sobre a sua eficácia. Relativamente ao protocolo de utilização, em 3 artigos o solvente foi aplicado apenas na fase inicial, antes da desobturação, e num deles apenas na fase final. Nos 3 artigos restantes o solvente foi depositado em dois momentos, na fase inicial e após desobturação. Em 2 artigos foi preconizada a ativação ultrasónica passiva do solvente após desobturação. Em 4 artigos a utilização de solvente não influenciou a remoção de material obturador, enquanto que em 3 resultou benéfica. Conclusões: São necessários mais estudos com metodologias e protocolos de utilização bem definidos para confirmar a utilidade dos solventes. A aplicação nos estádios finais do retratamento e a agitação de solventes específicos para a dissolução de ambos os materiais obturadores, guta-percha e cimento, poderá ser uma estratégia promissora.

http://doi.org/10.24873/j.rpemd.2019.12.581

\section{\#120 Efeito bactericida do Irrigun em canais radiculares contaminados com Enterococcus faecalis}

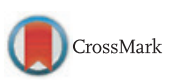

Luís França Martins*, João Espírito Santo, Mariana Seabra

\section{Medical Art Center}

Objetivos: A erradicação de bactérias dos canais radiculares constitui um desafio, sendo que sabemos atualmente, ser um fator crucial para o sucesso do TENC a longo prazo. Este ensaio in vitro avaliou o efeito bactericida do dispositivo Irrigun isoladamente e associado a soluções de hipoclorito de sódio ( $\mathrm{NaOCl}$ ) em canais radiculares contaminados experimentalmente com E. faecalis. Materiais e métodos: Sessenta dentes humanos uni-radiculares foram selecionados, após extração por motivos periodontais. Foram secionados por meio de disco metálico na junção amelo-cimentária, removendo a coroa. A amostra foi esterilizada a $134 .{ }^{\circ} \mathrm{C}$ por $12 \mathrm{mi}-$ nutos. Os espécimes foram então inoculados com E. faecalis (ATCC 29212) por 21 dias a $37^{\circ} \mathrm{C}$, até uma densidade de $2 \mathrm{Ma}$ cfarland ser alcançada (2,0x108 CFU/ml). Seis grupos foram formados (10 espécimes cada) por alocação randomizada: Grupos Controlo: G0 (não tratado) e G1 (irrigação com NaCl); Grupos de teste: G2 (5,25\% NaOCl), G3 (dispositivo Irrigun), G4 (dispositivo Irrigun e 5,25\% NaOCl irrigação) e G5 (dispositivo Irrigun e 0,5\% $\mathrm{NaOCl}$ irrigação). A permeabilização e pré-alargamento (Glyde Path e Pre-Flaring) foram obtidos pelo uso de limas $\mathrm{K}$ manuais (conicidade $2 \%$ ), e a instrumentação foi realizada utilizando o sistema de limas ProTaper ${ }^{\circledR}$ até lima F3 (S1; Sx; S1; S2; F1; F2; F3). A irrigação foi realizada de acordo com o grupo de tratamento. Efetuou-se a colheita com cones de papel estéreis; Estes foram colocados em tubos de centrífuga estéreis, diluídos e espalhados em placas Agar BHI, incubadas por $24 \mathrm{~h} / 37 .{ }^{\circ} \mathrm{C}$. Procedeu-se à contagem de unidades formadoras de colónias (UFC/ml), cálculo do Log Kill e percentagem redução bacteriana correspondente. A análise estatística baseou-se em testes não paramétricos $(\alpha=0,05)$. Resultados: Valores menores de UFC/ml em todos os grupos de teste comparativamente com os controlos (T.Mann- Whitney; $\mathrm{p}<0,001)$. Grupos G0 e G1, com 3,00E $9 \mathrm{UFC} / \mathrm{ml}$, Log kill=0 (p>0,05), G2 e G3 registaram 8,20E 5, Log kill=3,56, 99,97\% e 6,02E 5UFC/ml, Log kill=3,70, 99,98\% ( $p=0,970)$, respectivamente; Os grupos G4 e G5 registaram zero UFC/ml, Log kill=10,48, $100 \%$ não se detectando diferença $(p=0,664)$ entre a acção combinada do laser com 5,25\% ou 0,5\% NaOCl. Conclusões: Os efeitos bactericidas obtidos pelo laser são comparáveis aos obtidos pelo $\mathrm{NaOCl}$. O uso combinado do dispositivo Irrigun e $\mathrm{NaOCl} 5,25 \%$ ou $0,5 \%$ eliminou a presença de E.faecalis nos canais radiculares. Devem ser realizados mais ensaios para avaliação do efeito bactericida destes protocolos com outros microrganismos.

http://doi.org/10.24873/j.rpemd.2019.12.582

\section{\#121 Selagem apical de dois cimentos endodônticos após preparação do canal para espigão}

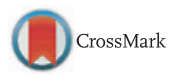

Kátia Porões Monteiro*, Ana Margarida Coelho Abrantes, Anabela Baptista Pereira Paula, Maria Filomena Rabaça Roque Botelho, Eunice Virgínia Valdez Faria Bidarra Palmeirão Carrilho, Manuel Marques Ferreira

Instituto de Endodontia- FMUC, iCBR, CIMAGO - FMUC, Unidade de Biofísica, IBILI - FMUC, Instituto de Clínica Integrada -FMUC, Área de Medicina Dentária, Faculdade de Medicina da Universidade de Coimbra

Objetivos: Após o tratamento endodôntico, é muitas vezes necessário colocar um espigão intrarradicular, o que implica a remoção parcial do material de obturação, podendo afetar a selagem apical. Tendo em conta este pressuposto, o objetivo deste estudo foi comparar a selagem apical provida pelo cimento AH Plus ${ }^{\circledR}$ e GuttaFlow Bioseal ${ }^{\circledR}$ após realização do preparo imediato do canal radicular para colocação de espigão. Materiais e métodos: Após preparação químico-mecânica 
com o sistema Protaper NextTM, 36 dentes monorradiculares foram divididos aleatoriamente entre 4 grupos. O grupo Controlo Positivo e o grupo Controlo Negativo foram compostos por 6 dentes. O grupo AH PLUS e o grupo BIOSEAL (compostos por 12 dentes cada) foram obturados através da técnica de compactação vertical com onda contínua, cone único de guta-percha e cimento AH Plus ${ }^{\circledR}$ e GuttaFlow Bioseal ${ }^{\circledR}$, respetivamente. Imediatamente após a obturação procedeu-se à preparação do canal radicular para colocação de espigão com brocas Gates Glidden número 1, 2 e 3 de modo a deixar 4 mm de material obturador remanescente. Após 7 dias avaliou-se a selagem apical através da abordagem com Medicina Nuclear e infiltração apical do radioisótopo Técnesio 99 Metastável (99mTc) sob a forma de uma solução isotónica de Pertecnetato de Sódio. Foram utilizados os valores das contagens médias por minuto adquiridas e foi feita a análise estatística dos resultados. Resultados: Todos os grupos apresentaram valores de microinfiltração apical. O grupo Controlo Positivo apresentou valores de microinfiltração superiores $(1,99 \pm 0,66)$ comparativamente aos restantes grupos, enquanto que o grupo Controlo Negativo tal como expectável, apresentou os menores valores $(0,08 \pm 0,05)$. O grupo AH PLUS apresentou uma microinfiltração de 1,30 $\pm 0,74$, significativamente superior ao grupo BIOSEAL $(0,52 \pm 0,17)$. Conclusões: Verificou-se a presença de uma selagem apical mais efetiva após preparação imediata do canal radicular para colocação de espigão quando utilizado o cimento GuttaFlow Bioseal ${ }^{\circledR}$ em comparação com o cimento AH Plus ${ }^{\circledR}$.

http://doi.org/10.24873/j.rpemd.2019.12.583

\section{\#122 Influência da contaminação sanguínea} na adesão de cimentos biocerâmicos à dentina

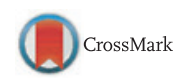

Sónia Cristina Rodrigues*, Joana Alexandra Marques Simões, Patrícia Diogo, Rui C. Paiva, Paulo Jorge Palma, João Miguel dos Santos

Instituto de Endodontia, Faculdade de Medicina da Universidade de Coimbra, Área de Medicina Dentária, Instituto Politécnico de Leiria, Departamento de Matemática da Escola de Tecnologia e Gestão

Objetivos: Este estudo tem como objetivo determinar a força de adesão de 4 cimentos biocerâmicos (ProRoot ${ }^{\circledR}$ MTA, Biodentine ${ }^{\mathrm{TM}}$, TotalFill BC RRM ${ }^{\mathrm{TM}}$ putty e um cimento experimental à base de polidimetilsiloxano) à dentina radicular, com e sem contaminação sanguínea, avaliada por testes de push-out. Materiais e métodos: Foram recolhidos 120 dentes humanos monorradiculares, seccionados com um comprimento radicular padronizado de $15 \mathrm{~mm}$ e os canais preparados até à broca Gates Glidden n. ${ }^{\circ} 4$. As amostras foram divididas em 4 grupos, de acordo com o material utilizado. Cada grupo foi dividido em 2 ( $n=15)$, de acordo com ausência ou presença de sangue nas paredes do canal. Os canais radiculares foram totalmente obturados com cada um dos cimentos e posteriormente armazenados em estufa a $37 .{ }^{\circ} \mathrm{C}$ com humidade relativa de 100\%. Após 1 semana, as amostras foram seccionadas em 3 segmentos, apical, médio e coronário, com a espessura de 3 $\mathrm{mm}$. Foi realizado o cálculo da área de adesão para cada amos- tra, a partir dos registos fotográficos das mesmas, recorrendo ao programa ImageJ. O teste de força de adesão push-out (MPa) foi realizado numa máquina de testes universais (Shimadzu AG-I) sendo obtido o valor máximo da força no momento de deslocamento do material. Foi ainda registado o tipo de falha. A análise estatística dos resultados foi realizada para um nível de significância de 0,05. Resultados: Os cimentos testados apresentavam diferenças estatisticamente significativas na força adesiva push-out. O cimento TotalFill BC putty apresentou os valores mais elevados de resistência ao deslocamento (10,31 MPa) e o Cimento experimental os valores mais baixos (1,13 MPa). A força adesiva observada para o TotalFill BC putty foi estatisticamente superior em relação ao Biodentine $(8,54$ $\mathrm{MPa})$ e ao ProRoot MTA (7,44 MPa). A presença de contaminação não alterou significativamente a força adesiva push-out, à exceção do cimento experimental em que se verificou uma diminuição desta $(p=0,0002)$. Não se verificam diferenças na resistência ao deslocamento para cada um dos materiais nas diferentes secções testadas $(p>0,05)$. Todos os grupos revelaram uma forte predominância de falhas adesivas. Conclusões: Para os materiais testados, o cimento que apresenta maior força de adesão à dentina foi o TotalFill BC putty. A presença de sangue na dentina não exerceu influência no desempenho dos materiais testados, com excepção do cimento experimental à base de polidimetilsiloxano, em que ocorreu uma diminuição.

http://doi.org/10.24873/j.rpemd.2019.12.584

\#123 Literacia em saúde dos estudantes do $1 .^{\circ}$ ano da FMDUL

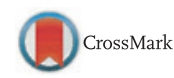

Maria Raposo Marques*, Henrique Luís, Sónia Mendes

FMDUL

Objetivos: A literacia em saúde é um mediador na relação entre educação e saúde e está relacionada com os cuidados de saúde, a prevenção de doença e a promoção de saúde. Este trabalho pretende avaliar a literacia em saúde e os fatores associados na população de alunos do $1 .^{\circ}$ ano da Faculdade de Medicina Dentária da Universidade de Lisboa. Materiais e métodos: Foi realizado um estudo observacional, analítico e transversal. A recolha dos dados foi realizada nas instalações da faculdade, aplicando um questionário e a versão portuguesa do instrumento Newest Vital Sign aos estudantes do $1 .^{\circ}$ ano. Foi realizada a análise descritiva das variáveis e na análise inferencial foram utilizados os testes Qui-quadrado, Mann-Whitney e Kruskall-Wallis ( $\alpha=0,05 \%)$. Resultados: A amostra foi constituída por 106 participantes, com uma média de idade de 19,48 anos. A maior parte dos participantes apresentou uma literacia em saúde adequada (71,7\%). O número médio de repostas corretas foi de 4,19 respostas. Apenas se verificou uma associação entre a literacia em saúde e a frequência de visita ao médico dentista ou higienista oral $(p=0,04)$. Conclusões: A maioria dos alunos do $1 .^{\circ}$ ano da FMDUL apresenta uma literacia em saúde adequada. Os alunos que frequentaram o médico dentista com mais regularidade apresentaram uma melhor literacia em saúde.

http://doi.org/10.24873/j.rpemd.2019.12.585 